\title{
Precise Control of Copper-Localized Surface Plasmon Resonance in the Near Infrared Region for Enhancement of Up-Conversion Luminescence
}

\author{
Yuyong Pan ${ }^{1} \oplus$, Lingling Chu ${ }^{1}$, Jiliang Liu ${ }^{1}$, Baize $\mathrm{Lv}^{1}{ }^{1}$, Laurence A. Belfiore ${ }^{1,2, *}$ and \\ Jianguo Tang $1, * \mathbb{D}$ \\ 1 Institute of Hybrid Materials, National Center of International Joint Research for Hybrid Materials \\ Technology, National Base of International Sci. \& Tech. Cooperation on Hybrid Materials, \\ Qingdao University, Qingdao 266071, China; 15610022310@163.com (Y.P.); cll1835526212@163.com (L.C.); \\ liuj10110555@163.com (J.L.); 17852153890@163.com (B.L.) \\ 2 Department of Chemical and Biological Engineering, Colorado State University, Fort Collins, CO 80523, USA \\ * Correspondence: belfiore@engr.colostate.edu (L.A.B.); tang@qdu.edu.cn (J.T.); \\ Tel.: +1-970-4915395 (L.A.B.); +86-532-8595-1519 (J.T.)
}

Received: 19 April 2020; Accepted: 7 May 2020; Published: 12 May 2020

\begin{abstract}
The surface plasmon resonance of copper in the near infrared region provides a novel method for enhancement of up-conversion luminescence compared to using gold and silver, as the former grants significant cost savings. In this study, we made a flat $\mathrm{Cu}$ film covered $\mathrm{TiO}_{2}$ to enhance the up-conversion fluorescence intensity. The results show that the deposition of copper/ $/ \mathrm{TiO}_{2}$ dioxide nanocomposite film prepared via spin-coating has no effect on the structure of $\mathrm{NaGdF}_{4}: \mathrm{Er}^{3+}, \mathrm{Yb}^{3+}$. The absorption wavelength of the copper film moved from the original visible wavelength $(\sim 600 \mathrm{~nm})$ range to the infrared wavelength after covering $\mathrm{TiO}_{2}$, and most obviously, the copper film covered two layers of $\mathrm{TiO}_{2}$ by about $16 \mathrm{~nm}$; the peak of the absorption appeared at $835 \mathrm{~nm}$ due to the enhanced excitation field. The behavior of the nanocomposite film with $\mathrm{NaGdF}_{4}: \mathrm{Er}^{3+}$ and $\mathrm{Yb}^{3+}$ under $980 \mathrm{~nm}$ excitation was investigated; it provides a novel way for studying mental-enhanced fluorescence. Besides, the peaks of the fluorescence spectrum show different emissions at $542 \mathrm{~nm}$ and $660 \mathrm{~nm}$, respectively. The copper nanoparticles-covered $\mathrm{TiO}_{2}$ layer can obviously enhance the fluorescence intensity, and the maximum enhancement factors of emission of $\mathrm{NaGdF}_{4}: \mathrm{Er}^{3+}$ and $\mathrm{Yb}^{3+}$ nanoparticles are 3.1 and 1.9 on the nanocomposite film, respectively.
\end{abstract}

Keywords: surface plasmon resonance; mental enhancement fluorescence; enhanced up-conversion emission; copper nanoparticles

\section{Introduction}

In the last decade, up-conversion fluorescence intensity has attracted widespread attention for improving optics for a variety of applications [1,2]. For example, detecting bioprobes for optical tracking [3], biological imaging [4], photodynamic therapy [5], 3D displays [6,7] and solar energy conversion [8]. For example, $\mathrm{NaGdF}_{4}: \mathrm{Er}, \mathrm{Yb}$ is known as a popular material for up-conversion luminescence [9-12]. Compared to the conventional fluorescent materials, the up-conversion has a different process which can lower the energy of a photon to stimulate higher energy photons [13]. The up-conversion process occurs by absorbing $980 \mathrm{~nm}$ laser irradiation and then successively transfering the excitation energy to nearby co-doped activators $\left(\mathrm{Ho}^{3+}, \mathrm{Er}^{3+}, \mathrm{Tm}^{3+}\right.$, etc.) [14]. The sensitizer $\mathrm{Yb}$ dopant ions can absorb $980 \mathrm{~nm}$ photons and then transfer them to an adjacent activator (Er), which emits luminescence with a short wavelength. The wavelength of up-conversion emissions can be tuned in the ultraviolet, visible and near-infrared regions [15-17]. Subsequently, 
$\mathrm{Er}^{3+}, \mathrm{Yb}^{3+}$ co-doped in $\mathrm{NaGdF}_{4}$ becomes the promising visible-light-emitting phosphor which has two obvious peaks: one is green emission at $550 \mathrm{~nm}$ and one is red emission at $660 \mathrm{~nm}$ under the $980 \mathrm{~nm}$ excitation [18]. Compared with fluorescent organic dyes [19-21] and semiconductor nanocrystals [22,23], the up-conversion material has lots of advantages, such as non-toxicity, chemical stability, a long lifetime and a strong emission in the visible spectrum. Moreover, the near infrared excitation was consistent with the light source used in clinical disease treatment and it did not cause damage on the human body. In spite of various advantages, the quantum efficiency [24] of up-conversion luminescence is very low due to the small absorption at $980 \mathrm{~nm}$. Some approaches can enhance the intensity of up-conversion fluorescence, such as surface plasmon coupling [25,26], varying the doped element, changing the dopant concentration of ions [8], transforming the energy and controlling the sizes of up-conversion nanoparticles [27]. In the above-mentioned approaches of fluorescence enhancement, the surface plasmon $[26,28-30]$ was recognized as the most effective one to enhance the up-conversion fluorescence. However, this approach has limitations in nanobiophotonics-size limitations especially.

The noble mental nanoparticles such as gold $(\mathrm{Au})$ and silver $(\mathrm{Ag})$ show strong surface plasmon resonance, which is considered the efficient way to enhance the up-conversion fluorescence. The high-energy local electric field of the plasmon [31] on the surface of nanomaterials has the characteristic of enhancing resonance in nonlinear optical processes, which can increase the excitation efficiencies of high-level electrons of up-conversion materials to obtain a high probability of radiation photon transition [32]. As the same time, increased excitation rate can increase the fluorescence lifetime of an up-conversion material [33]. It is well known that the gold nanorods have two distinct absorptions and the silver ones have a narrow absorption peak which provides a method of up-conversion enhancement. Thus, researchers studied the effects of noble metal nanoparticles for enhancing the up-conversion fluorescence. In 2016, Manurung et al. fabricated gold (Au) sandwich, in silica coated $\mathrm{NaYF}_{4}: \mathrm{Yb}$, Er up-converted nanoparticles for mental enhanced fluorescence [34]. In 2017, Chen et al. fabricated an $\mathrm{Au}-\mathrm{Ag}$ nanocage@NaYF${ }_{4} @ \mathrm{NaYF}_{4}: \mathrm{Yb}$, Er core-shell hybrid for the tunable up-conversion enhancement [35]. In 2017, Wang et al. fabricated the Cap Ag/PMMA ordered platform for remarkable enhancement of up-conversion luminescence and trademark anticounterfeiting [36]. Although the gold and silver nanoparticles show relatively good performance in enhancing the fluorescence of up-conversion, problems remain, such as the expensive prices of gold and silver for the experiments, and testing in solution making it difficult to eliminate the influence of aggregation reactions between samples and mutual reflection between nanomaterials. As the same time, compared with gold and silver nanoparticles obtained by the method of sputtering, copper nanoparticles show a wide absorption, and the peak of absorption appears at about $600 \mathrm{~nm}$, which is more suitable for biological sensor applications than the peaks of absorption of gold and silver at $530 \mathrm{~nm}$ and $400 \mathrm{~nm}$, respectively. Moreover, copper nanoparticles exposed to the air are easily oxidized, and this would make them unusable in biosensor applications. Thus, the $\mathrm{TiO}_{2}$ film is considered an optional material to protect nanoparticles from oxidation. Thus, the research on copper nanoparticles is very important, as the $\mathrm{Cu} / \mathrm{TiO}_{2}$ film shows a strong resonance peak in the infrared region. Copper nanoparticles also exhibit satisfactory surface-plasma-enhanced fluorescence properties. As the same time, the copper nanoparticles can be simply prepared by sputtering. However, few works have investigated the surface plasmon effect of copper on the enhancement of up-conversion fluorescence.

In the current paper, we describe the preparation of a novel $\mathrm{Cu} / \mathrm{TiO}_{2}$ film in which the copper nanoparticles are made by sputtering, and the $\mathrm{TiO}_{2}$ used is deposited by spin-coating on the copper nanoparticles. The resonance wavelength was redshifted to infrared band $(835 \mathrm{~nm})$ which matches with the excitation of $\mathrm{NaGdF}_{4}$. The maximum ratios of intensity of $\mathrm{NaGdF}_{4}: \mathrm{Er}, \mathrm{Yb}$ fluorescence at $542 \mathrm{~nm}$ and $660 \mathrm{~nm}$ were 3.1 and 1.9, respectively. Thus, the special structure has a significant effect on the intensity of up-conversion fluorescence. Besides the non-linear luminescence mechanism of $\mathrm{NaGdF}_{4}: \mathrm{Er}, \mathrm{Yb}$, the high-energy local electric field on the surface of the hybrid film can increase the chance of photon transition and then enhance the up-conversion fluorescence. Duration, morphological characterization and evolution of absorption are systematically investigated with the fabrication of copper nanoparticles and $\mathrm{TiO}_{2}$ film on the quartz glass substrate. For the $\mathrm{Cu} / \mathrm{TiO}_{2}$ film, $\mathrm{SEM}$ and 
AFM show size changes of nanoparticles and the thickness of the film. The absorption spectrum was witnessed along with $\mathrm{TiO}_{2}$ film thickness changing.

\section{Materials and Methods}

\subsection{Materials}

Acetone, alcohol, titanium butoxide $(>99 \%, M w=340.32)$, 2-Methoxyethanol $(M w=76.09, \mathrm{AR})$, methanol (99.5\%, Mw = 32.04, AR), $\mathrm{GdCl}_{3} \cdot 6 \mathrm{H}_{2} \mathrm{O}(99 \%, M w=371.60), \mathrm{YbCl}_{3} \cdot 6 \mathrm{H}_{2} \mathrm{O}(99.99 \%$ metals basis, $M w=387.49), \mathrm{ErCl}_{3} \cdot 6 \mathrm{H}_{2} \mathrm{O}(99.995 \%$ metals basis, $M w=381.71)$, oleic acid $(M w=282.47, \mathrm{AR})$, octadecene ( $>90.0 \%(\mathrm{GC}), M w=252.48), \mathrm{NaOH}(96 \%, M w=40, \mathrm{AR})$ and $\mathrm{NH}_{4} \mathrm{~F}(\geq 99.99 \%$ metals basis, $M w=37.04)$ were purchased from Sigma-Aldrich (St. Louis, MO, USA). All reagents were used as received without further purification. Quartz glass was obtained from Alibaba (Shanghai, China).

\subsection{Preparation of Substrate}

The glass quartz plate used in this work was $1 \mathrm{~mm}$ in thickness; the length and width were $1.5 \mathrm{~cm}$ respectively. Before fabrication, the quartz plate was ultrasonically-cleaned in acetone and alcohol at room temperature for $30 \mathrm{~min}$, and then washed in ultrapure water. When dried in slowing nitrogen, the glass sheet was degassed in a rapid annealing furnace at $600{ }^{\circ} \mathrm{C}$ for $15 \mathrm{~min}$ under a $5 \mathrm{~Pa}$ vacuum.

\subsection{Sample Fabrication}

Copper deposition was performed by magnetron sputtering with a deposition rate of $1 \mathrm{~nm} / \mathrm{s}$ and an ionization current of $15 \mathrm{~mA}$ under a $10 \mathrm{~Pa}$ Ar atmosphere. In the study of surface topography, the copper film is deposited by precisely controlling the deposition time. In the annealing process, the samples were heated from the ambient $\left(\sim 25^{\circ} \mathrm{C}\right)$ to the target temperature $\left(900^{\circ} \mathrm{C}\right)$ with a ramp rate of $80{ }^{\circ} \mathrm{C} \cdot \mathrm{s}^{-1}$ under $\mathrm{N}_{2}$ atmosphere. The temperature was raised to $900{ }^{\circ} \mathrm{C}$ with an annealing duration of $1800 \mathrm{~s}$ to guarantee the sufficient surface diffusion. We used titanium butoxide $(0.34 \mathrm{~g})$ and 2-methoxyethanol $(10 \mathrm{~mL})$ in the process of making the titanium dioxide precursor solution and mixed the solution thoroughly to keep the solution stable. The mixed solution appears a faint yellow color and can remain stable at all times. Deposition of $\mathrm{TiO}_{2}$ film was achieved by spin-coating at $3000 \mathrm{rpm}$, and then the sample was post-annealed at $550{ }^{\circ} \mathrm{C}$ with the annealing time of $3600 \mathrm{~s}$. For the process of making up-conversion materials, we added $2 \mathrm{~mL}$ of methanol into $\mathrm{GdCl}_{3} \cdot 6 \mathrm{H}_{2} \mathrm{O}(0.289 \mathrm{~g}$, $0.78 \mathrm{mmol}), \mathrm{YbCl}_{3} \cdot 6 \mathrm{H}_{2} \mathrm{O}(0.074 \mathrm{~g}, 0.2 \mathrm{mmol})$ and $\mathrm{ErCl}_{3} \cdot 6 \mathrm{H}_{2} \mathrm{O}(0.0076 \mathrm{~g}, 0.02 \mathrm{mmol})$ in a three-necked flask and ultrasonically mixed the solution. As the same time, oleic acid $(8 \mathrm{~mL})$ and octadecene $(12 \mathrm{~mL})$ were added to the flask. Evacuation is required before and during heating to remove oxygen from the flask and methanol from the solution. We used gradient heating from the ambient temperature $\left(\sim 25^{\circ} \mathrm{C}\right)$ to $150^{\circ} \mathrm{C}$ to ensure the nanoparticles' size is uniform and hold for $30 \mathrm{~min}$ at 70,110 and $150{ }^{\circ} \mathrm{C}$, respectively. Then, we used the room temperature cooling method to reduce the temperature to $50^{\circ} \mathrm{C}$ for adding $\mathrm{NaOH}(0.1 \mathrm{~g}, 2.5 \mathrm{mmol})$ and $\mathrm{NH}_{4} \mathrm{~F}(0.148 \mathrm{~g}, 4 \mathrm{mmol})$. The mixed solution was heated to $300{ }^{\circ} \mathrm{C}$ for half an hour and cooled to room temperature. Deposition of the up-conversion material film was achieved by spin-coating with the revolutions per minute of 2000. One consideration is to keep the material on the sample as much as possible, and the other is to make the film more uniform.

\subsection{Characterization}

The morphologies of $\mathrm{Cu}$ structure and up-conversion materials were characterized by scanning electron microscopy (SEM), transmission electron microscopy (TEM), micro-spectrophotometer, fluorescence detection equipment (FLS-1000), X-ray diffraction (XRD) and the photo-induced force microscope (PiFM). Topographies of the surfaces of $\mathrm{Cu}$ films were detected using PiFM from Molecular Vista, Inc. (San Jose, CA, USA). Micrographs of $\mathrm{Cu}$ films and coper nanoparticles with different thickness $\mathrm{TiO}_{2}$ were detected using a FEG 650 SEM (Carl Zeiss SMT, Oberkochen, Germany). Absorbances of copper and copper with $\mathrm{TiO}_{2}$ were characterized by a CRAIC 20/30 PVTM microspectrophotometer 
(CRAIC, San Dimas, CA, USA). Transmission electron microscopy (TEM) images of $\mathrm{NaGdF}_{4}: \mathrm{Er}^{3+}$, $\mathrm{Yb}^{3+}$ nanoparticles were observed using a JEOL 2100 transmission electron microscope (JEOL, Tokyo, Japan). The XRD pattern was obtained by an X-ray diffractometer (Bruker D8 Advance, Bruker, Germany) with the scanning speed of $2^{\circ} / \mathrm{min}$. The up-conversion spectra of $\mathrm{NaGdF}_{4}: \mathrm{Er}^{3+}, \mathrm{Yb}^{3+}$ were obtained with a FLS-1000 spectrophotometer (Edinburgh Inc., Livingston, UK) upon $980 \mathrm{~nm}$ excitation.

\section{Results and Discussion}

Figure 1 shows the surface topography of copper nanoparticles on quartz glass at the annealing temperature of $900^{\circ} \mathrm{C}$ with different $\mathrm{Cu}$ deposition times, and the diameter distribution histograms of copper nanoparticles are shown. The detailed morphology of $\mathrm{Cu}$ nanostructures is characterized by the atomic force microscope (AFM) in Figure 1a and scanning electron microscope (SEM) in Figure 1c-f. Figure 1a shows the AFM topography image of the copper nanoparticles. It is obvious that the height difference of the copper nanoparticles is about $73.6 \mathrm{~nm}$ in the AFM image, which illustrates that the $\mathrm{Cu}$ film was stimulated by nanoparticle formation at the annealing temperature. The yellow areas in Figure 1a represent nanoparticles with higher protrusions. Corresponding to the 3D image in Figure 1b, the results show a certain distance between the nanoparticles and show island-like shapes. As the same time, $\mathrm{Cu}$ nanoparticles fabricated with different deposition times were studied by SEM. It is obvious that the samples at different deposition times have different nanoparticle sizes. The size of nanoparticles distributes between 40 and $220 \mathrm{~nm}$, as evidenced by the histograms in Figure 1g-j. Additionally, it can also be seen that the particle size distribution conforms to the normal distribution, and the calculated average sizes of nanoparticles with different deposition times are 53, 62, 100 and $120 \mathrm{~nm}$, respectively. The cause of the differing sizes of nanoparticles may be explained by the following mechanism. When the copper deposition time is fixed and the heating temperature is $900{ }^{\circ} \mathrm{C}$, it is generally agreed that the film is split into nanoparticles [37]. The process of forming a $\mathrm{Cu}$ nanostructure from a uniform $\mathrm{Cu}$ film can be explained based on solid state dewetting (SSD) [38-40]. As the deposition temperature was near the ambient $\left(\sim 25^{\circ} \mathrm{C}\right)$, the as-deposited copper films have defects and vacancies which can offer favor sites for the high temperature nucleation. When sufficient energy is applied, vacancies can further develop on the surface of the $\mathrm{Cu}$ film. As the temperature further increases, the voids will grow as the surface diffusion of copper atoms increases [37]. As with the influence of the heating temperature of $900^{\circ} \mathrm{C}$, the degree of aggregation of the surrounding nanoparticles changes with the effect of Ostwald ripening [41,42]. Similarly, the shape of the nanoparticles also shows a different trend. As the deposition time increases, the shape of the copper nanoparticles gradually changed from spherical to irregular [37].

The SEM image of copper nanoparticles and the corresponding elemental mappings by EDS are shown in Figure 2. Si, O and $\mathrm{Cu}$ were observed in the sample, and the peaks of $\mathrm{Si}, \mathrm{O}, \mathrm{Cu}$ and $\mathrm{Pt}$ can be found in the EDS spectra. Since the sample was fabricated directly on the quartz substrate, the measured $\mathrm{Si}$ and $\mathrm{O}$ contents account for most of the color observed in Figure 2c,d. Before testing, we sputtered $\mathrm{Pt}$ with a nanoparticle size of $20 \mathrm{~nm}$ on copper nanoparticles to increase the conductivity of the sample and observe nanoparticle topography from charge accumulation at higher magnifications. From Figure 2a to Figure 2b, the amount of copper deposition increased and the proportion of the $\mathrm{Cu}$ element increased. It can be seen in Figure 2a that the time of sputtering for copper was less than it was the Figure $2 \mathrm{~b}$, and the $\mathrm{Cu}$ in Figure 2a accounts for $5.54 \%$. The longer sputtering time evidenced by the proportion of $\mathrm{Cu}$ accounts for $9.35 \%$. This also proves that the copper nanoparticles remaining on the substrate increase with increasing deposition time. The blue dots in Figure 2c,d show the magnification of copper nanoparticles, which also corresponds to the SEM image. The island-like distribution is also confirmed by Figure 2c,d's copper distribution caused by the SSD growth mechanism [41,42]. 

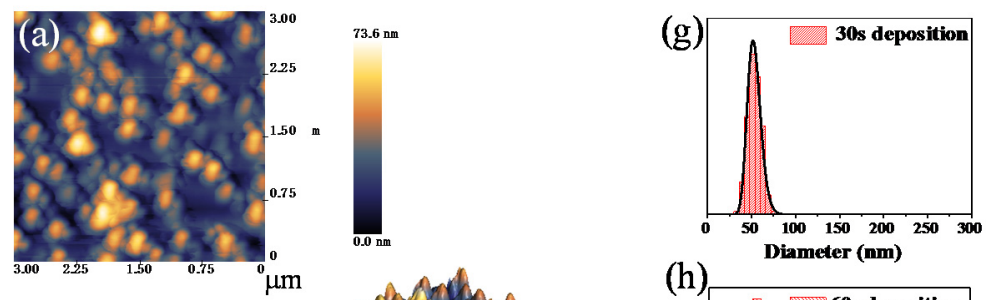

\section{(b)}
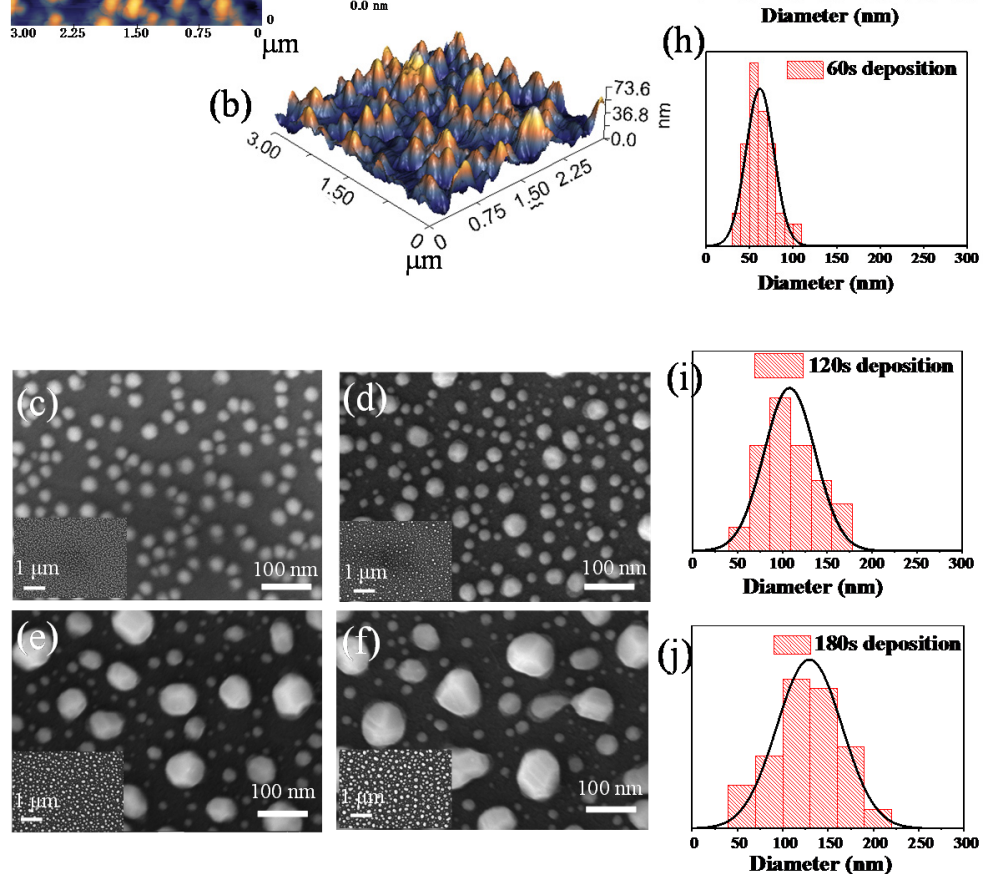

Figure 1. (a) Atomic force microscope (AFM) top-view of $3 \times 3 \mu \mathrm{m}^{2}$ of copper nanoparticles; (b) corresponding the 3D image; (c-f) SEM images of copper nanoparticles with different deposition times between 30 and $180 \mathrm{~s}$ fabricated at $900{ }^{\circ} \mathrm{C} ;(\mathbf{g}-\mathbf{j})$ corresponding diameter distribution histograms.
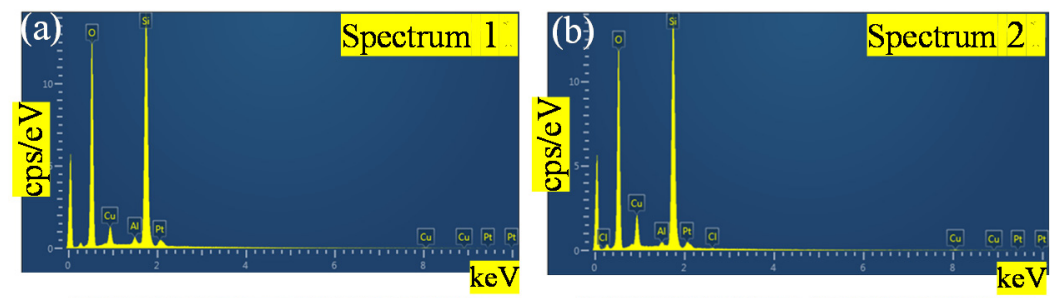

(c)
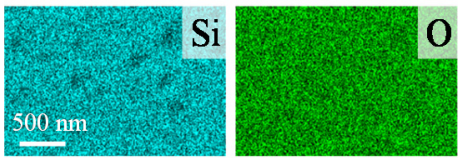

(d)
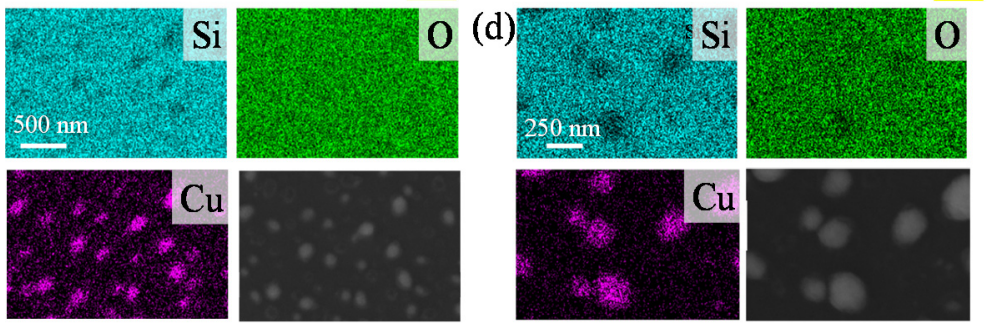

Figure 2. Energy dispersive X-ray spectroscopy (EDS) elemental characterization of the copper nanoparticles fabricated with the different deposition times at $900{ }^{\circ} \mathrm{C} ;(\mathbf{a}, \mathbf{c})$ the EDS spectra of the copper for a deposition time of $90 \mathrm{~s} ;(\mathbf{b}, \mathbf{d})$ the EDS spectra of the copper for a deposition time of $120 \mathrm{~s}$.

Furthermore, we studied the SEM side-views of copper nanoparticles coated with $\mathrm{TiO}_{2}$. $\mathrm{The}^{\mathrm{TiO}_{2}}$ layers were deposited using spin-coating and then annealed at $550{ }^{\circ} \mathrm{C}$ under ambient air for $1 \mathrm{~h}$. The schematic illustration of the copper nanoparticles covered with $\mathrm{TiO}_{2}$ can be seen in Figure 3a; it is obvious that the structure is similar to the physical model we expected to build, as shown in Figure $3 \mathrm{~b}-\mathrm{d}$. The arrows point exactly to the copper nanoparticles and $\mathrm{TiO}_{2}$ films we synthesized, 
respectively. Thus, we can see that the copper nanoparticles are also island-like when they are covered with oxides, and the oxide coating was made on the copper nanoparticles with layers of about $40 \mathrm{~nm}$ in thickness (Figure 3d). Figure 3c,d shows different sizes of copper nanoparticles covered in $\mathrm{TiO}_{2}$ between 119 and $155 \mathrm{~nm}$ thick. The presence of oxide can also be seen in the divided areas between the copper nanoparticles, which shows that the uniformity of the film is perfect when spin-coating. The copper nanoparticles are tightly wrapped by the titanium dioxide, which can change the LSPR [1,43] of the metal nanoparticles. After measuring the structure by SEM and AFM, the absorption of the material structure was also investigated to show the absorbance change.

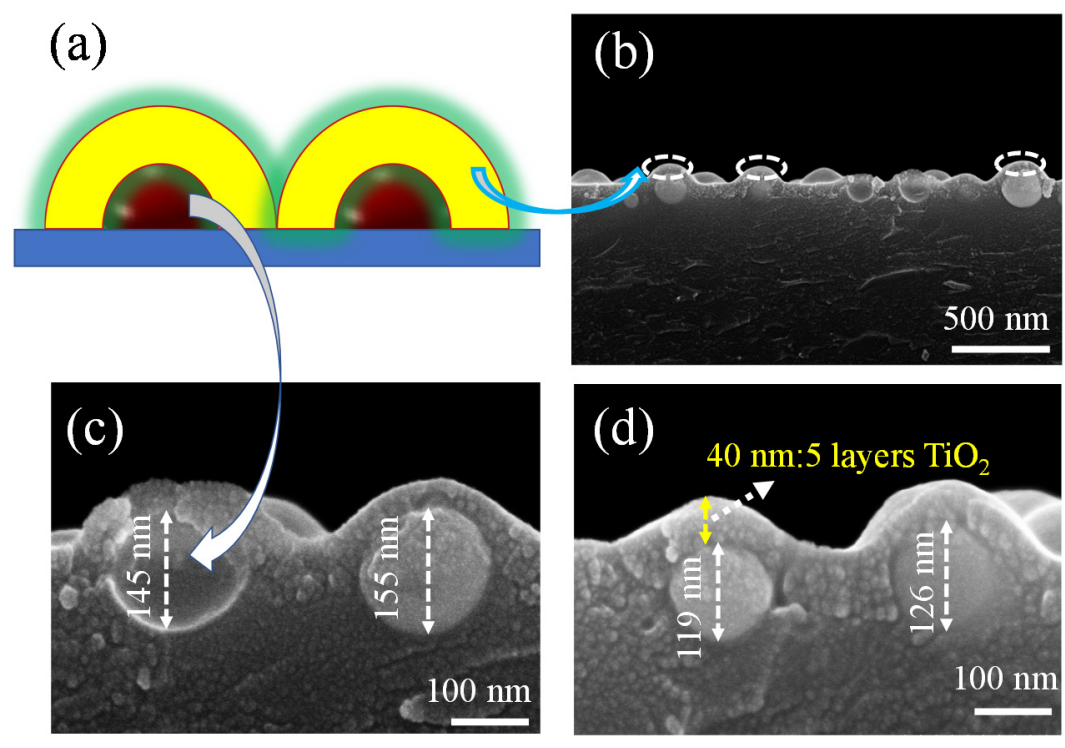

Figure 3. (a) Schematic illustrations of the $\mathrm{Cu} / \mathrm{TiO}_{2}$ composite film: the arrows represent copper nanoparticles and $\mathrm{TiO}_{2}$ films, respectively. (b) SEM side-view of the $\mathrm{Cu} / \mathrm{TiO}_{2}$ composite film. (c,d) Enlarged SEM side-views of the $\mathrm{Cu}$ nanoparticles covered with $\mathrm{TiO}_{2}$ of varying thickness.

Figure $4 \mathrm{a}-\mathrm{d}$ shows absorbance evolution by varying $\mathrm{TiO}_{2}$ thickness on copper nanoparticles of different sizes. Absorption spectra as recorded using a CRAIC 20/30 PVTM microspectrophotometer in the wavelengths varying from 200 to $2000 \mathrm{~nm}$ (Figure 4a-d) show the absorption spectra of nanoparticles at 200-1400 nm. The surface plasmon resonance band (SPR) [44,45] of the copper nanoparticles varies from $570 \mathrm{~nm}$ to $580 \mathrm{~nm}$. The absorption maximum of each sample corresponds to that of the surface plasmon band of the copper nanoparticles. With the increase of copper deposition time, the intensity of the absorption also increases and the absorption of copper nanoparticles has a $10 \mathrm{~nm}$ red shift due to the particle size increase with the time of copper deposition. At the same time, the absorption of copper nanoparticles covered by 1-layer or 2-layers $\mathrm{TiO}_{2}$ is also studied in Figure 4 . The absorption spectra of different samples exhibited the obvious absorption bands between 670 and $770 \mathrm{~nm}$ and 765 and $835 \mathrm{~nm}$ originating from the SPR $[44,45]$ of the copper nanoparticles with $\mathrm{TiO}_{2}$, and the absorption spectra of $\mathrm{TiO}_{2}$ appear at $330 \mathrm{~nm}$. It is obvious that the second peak is the absorption of copper nanoparticles covered with $\mathrm{TiO}_{2}$, and the absorption peak of copper nanoparticles whether covered one layer or two layers of $\mathrm{TiO}_{2}$ has an obvious red-shift compared to the absorption of pure copper nanoparticles. The absorption has maximum red shifts of 160 and $235 \mathrm{~nm}$ compared to the peak of pure copper nanoparticles appearing at about $600 \mathrm{~nm}$, respectively. The reason for the red shift is mainly due to the size effect of copper nanoparticles [46]. Additionally, the metal nanoparticles significantly increase light absorption and produce a plasmon resonance frequency shift of the absorption peak. In the meantime, the red shift of absorption of copper nanoparticles covered in $\mathrm{TiO}_{2}$ depends on the modulation of dielectric environment [47], and the absorption peak of copper nanoparticles has much more red shift compared to the isolated copper nanoparticles. Thus, the absorption peak position of the nanoparticles 
reached $835 \mathrm{~nm}$ from the original $570 \mathrm{~nm}$. As the same time, it is obvious that the copper deposition time of $150 \mathrm{~s}$ covered in two layers of $\mathrm{TiO}_{2}$ has a wider absorption band than the other samples.
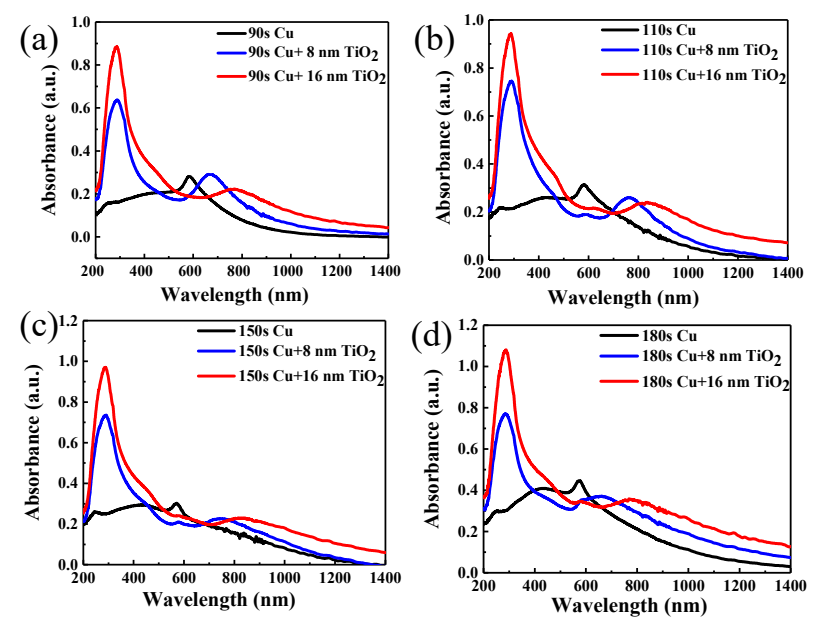

Figure 4. Absorbance evolution with $\mathrm{TiO}_{2}$ thickness on copper nanoparticles with different deposition times: (a) $90 \mathrm{~s}$, (b) $110 \mathrm{~s}$, (c) $150 \mathrm{~s}$, (d) $180 \mathrm{~s}$.

Figure 5 shows the change of absorbance peak position and absorbance peak position of copper nanoparticles covered by $\mathrm{TiO}_{2}$ of different thickness. As the same time, we can obtain that the absorbance peak has a red shift when the surfaces of copper nanoparticles are covered in one or two layers $\mathrm{TiO}_{2}$. The biggest change of the absorption peak is from the original $580 \mathrm{~nm}$ to about $830 \mathrm{~nm}$ can be seen in Figure 5a. But the 180 s copper deposition covered 2 layers $\mathrm{TiO}_{2}$ does not perform as well as other samples and the maximum absorption appear at $750 \mathrm{~nm}$. At the same time, the intensity of absorption is also one of important factors in terms of fluorescence enhancement. We can see that the intensity of the absorption peak showing a downward trend in Figure 5b. When the absorption peak position reaches the near infrared band, it must also ensure the absorption intensity. Thus, the time of $90 \mathrm{~s}, 110 \mathrm{~s}, 150 \mathrm{~s}$ coper deposition covered $\mathrm{TiO}_{2}$ are selected samples to study the enhancement of fluorescence.
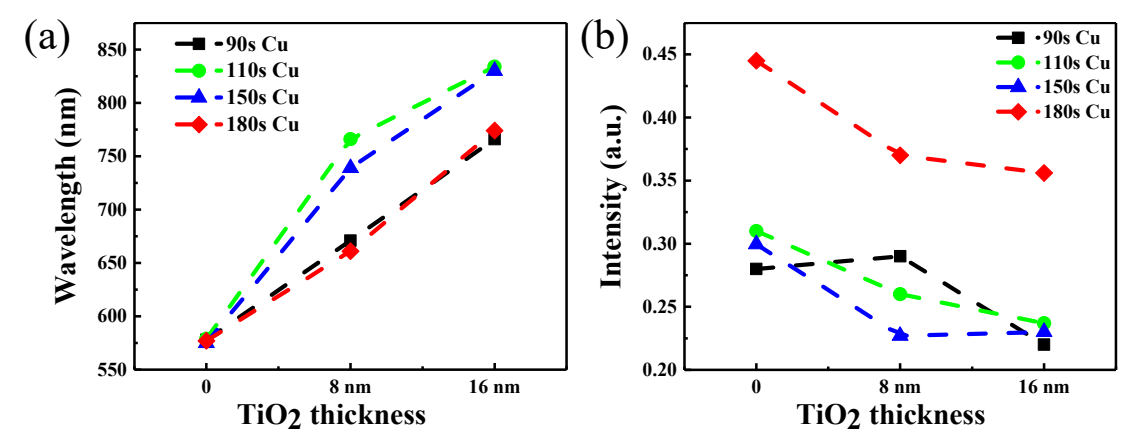

Figure 5. (a) The change of absorbance peak position of copper nanoparticles covered by $\mathrm{TiO}_{2}$ of different thickness, (b) the change of the peak absorbance position of copper nanoparticles covered by $\mathrm{TiO}_{2}$ of various thicknesses.

In the synthesis of the $\mathrm{NaGdF}_{4}: \mathrm{Yb}^{3+}, \mathrm{Er}^{3+}$ nanoparticles, we adopted hydrothermal method. When the heating temperature was selected, the operation was carried out by heating between zones while maintaining a certain temperature for half an hour to keep the size of $\mathrm{NaGdF}_{4}: \mathrm{Yb}^{3+}$, $\mathrm{Er}^{3+}$ nanoparticles uniform. As the same time, the size is typically $\sim 9 \mathrm{~nm}$ in the TEM image and the size distribution can be seen in Figure $6 \mathrm{a}, \mathrm{b}$. The particles size varies from 6 to $12 \mathrm{~nm}$ and it fits to the normal distribution. Figure $6 \mathrm{c}$ shows the XRD patterns $\mathrm{NaGdF}_{4}: \mathrm{Yb}^{3+}, \mathrm{Er}^{3+}$ nanoparticles. 
The diffraction peaks in Figure $6 \mathrm{c}$ at $29.6^{\circ}, 42.7^{\circ}, 53.4^{\circ}$ match well with XRD peaks of the standard cards (JCPDS:27-0699) of $\mathrm{NaGdF}_{4}: \mathrm{Yb}^{3+}, \mathrm{Er}^{3+}$ because of X-ray diffraction of the (1 011$),\left(\begin{array}{lll}2 & 0 & 1\end{array}\right)$ and $\left(\begin{array}{lll}2 & 1 & 1\end{array}\right)$ facets [48]. The spectrum of the measured sample is consistent with the standard card, indicating that the material formed a certain lattice structure which can be seen in Figure 6a. The up-conversion material was also spin-coated on top of the copper nanoparticles and then the basic fluorescence test was performed after a simple curing process by drying at room temperature.

\section{(a)}

(c)
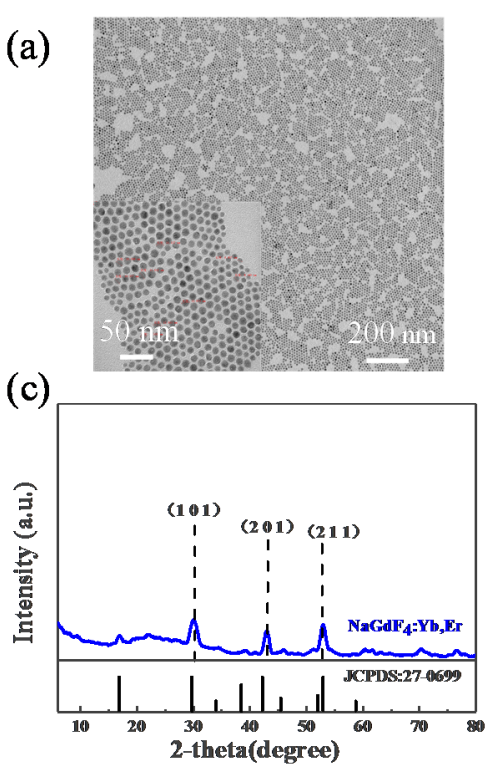

(b)

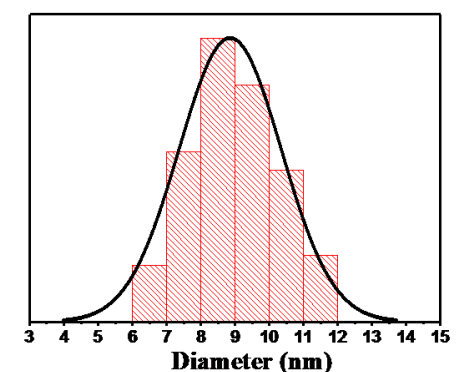

(d)

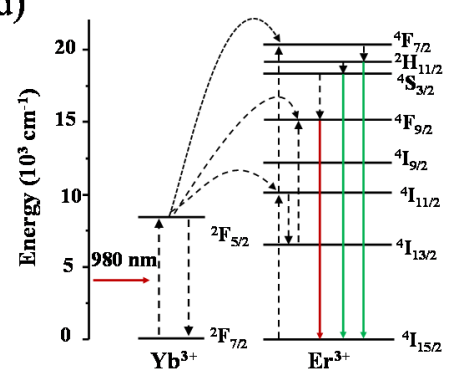

Figure 6. (a) TEM image of $\mathrm{NaGdF}_{4}: \mathrm{Yb}$, Er nanoparticles; (b) corresponding diameter distribution histogram; (c) XRD pattern of $\mathrm{NaGdF}_{4}: \mathrm{Yb}, \mathrm{Er}$; (d) the mechanism of up-conversion processes of $\mathrm{NaGdF}_{4}: \mathrm{Yb}, \mathrm{Er}$.

The $\mathrm{NaGdF}_{4}$ can be known as the popular material for up-conversion luminescence and under $980 \mathrm{~nm}$ excitation [9], $\mathrm{NaGdF}_{4}$ can have green and red emission doping $\mathrm{Yb}^{3+}, \mathrm{Er}^{3+}$. Figure $6 \mathrm{~d}$ is the mechanism of up-conversion processes of $\mathrm{NaGdF}_{4}: \mathrm{Yb}^{3+}, \mathrm{Er}^{3+}, \mathrm{Yb}^{3+}$ absorbs the energy of the $980 \mathrm{~nm}$ which the energy can transfers into $\mathrm{Er}^{3+}$ and $\mathrm{Er}^{3+}$ return to ground state from excited state [49]. Energy level schematic can be explained by the following theory. First, the electrons of $\mathrm{Yb}$ ions can change from ${ }^{2} \mathrm{~F}_{7 / 2}$ to ${ }^{2} \mathrm{~F}_{5 / 2}$ under the laser of $980 \mathrm{~nm}$, which can influence the electrons of Er ions from ${ }^{4} \mathrm{I}_{15 / 2}$ to ${ }^{4} \mathrm{I}_{11 / 2}$ [35]. As the same time, a part of electrons changes from ${ }^{4} \mathrm{I}_{11 / 2}$ to ${ }^{4} \mathrm{I}_{13 / 2}$ by the non-radiative method on the surface of up-conversion nanoparticles. Then adjacent $\mathrm{Yb}$ ions can absorb electrons and influence the Er ions which can change the energy state of Er ions from ${ }^{4} \mathrm{I}_{11 / 2}$ to ${ }^{4} \mathrm{~F}_{7 / 2}$ or from ${ }^{4} \mathrm{I}_{13 / 2}$ to ${ }^{4} \mathrm{~F}_{9 / 2}$. And on the ${ }^{4} \mathrm{~F}_{7 / 2}$ energy level of Er ions to ${ }^{2} \mathrm{H}_{11 / 2}$ and ${ }^{4} \mathrm{~S}_{3 / 2}$ by the method of non-radiative which can cause the green emission of ${ }^{2} \mathrm{H}_{11 / 2} \rightarrow{ }^{4} \mathrm{I}_{15 / 2}$ and ${ }^{4} \mathrm{~S}_{3 / 2} \rightarrow{ }^{4} \mathrm{I}_{15 / 2}$. As the same time, on the ${ }^{4} \mathrm{~F}_{9 / 2}$ energy level of Er ions can radiate to the ground state which generate ${ }^{4} \mathrm{~F}_{9 / 2} \rightarrow{ }^{4} \mathrm{I}_{15 / 2}$ transitions $[36,50]$. Thus, the green emission from $515 \mathrm{~nm}$ to $530 \mathrm{~nm}$ and $530 \mathrm{~nm}$ to $550 \mathrm{~nm}$ is determined by ${ }^{2} \mathrm{H}_{11 / 2} \rightarrow{ }^{4} \mathrm{I}_{15 / 2}$ and ${ }^{4} \mathrm{~S}_{3 / 2} \rightarrow{ }^{4} \mathrm{I}_{15 / 2}$ transitions. The red emission is attributed to the ${ }^{4} \mathrm{~F}_{9 / 2} \rightarrow{ }^{4} \mathrm{I}_{15 / 2}$ transitions. Here in this work, the $542 \mathrm{~nm}$ and $660 \mathrm{~nm}$ emission are our targeted.

During the fluorescence test, we selected samples of copper nanoparticles at different deposition times of 2-layer $\mathrm{TiO}_{2}$, and also performed a bare control. There are two obvious fluorescence emission peaks of the $\mathrm{NaGdF}_{4}: \mathrm{Yb}$, Er nanoparticles: green emission at $542 \mathrm{~nm}$ and red emission at $660 \mathrm{~nm}$ in Figure 7a. The intensity of fluorescence measured directly on quartz glass is weak as the amount of up-conversion material left on the glass sheet by spin coating is very low, and there is a dramatic enhancement observed in the measured fluorescence when the up-conversion material spin-coating on the $\mathrm{Cu} / \mathrm{TiO}_{2}$ structure. This also illustrates that the localized surface plasmon resonance (LSPR) peak plays a role in luminescence enhancement of up-conversion nanoparticles. The SPR of the $\mathrm{Cu} / \mathrm{TiO}$ red 
shifted to $835 \mathrm{~nm}$, matching well with the excitation wavelength, as can be seen in Figure 4 . The ratio of different fluorescence emission is recorded in Figure $7 \mathrm{~b}$. It can be seen that as the time of copper deposition covered $\mathrm{TiO}_{2}$ increases, the maximum fluorescence ration overall increases gradually. Thus, with the LSPR peak is turned to $835 \mathrm{~nm}$, the ratios of green and red emission can be about 3 and 2 times, respectively. The results show the LSPR with the excitation field can influence the up-conversion luminescence and then cause a strength enhancement of the local excitation field [35].

(a)

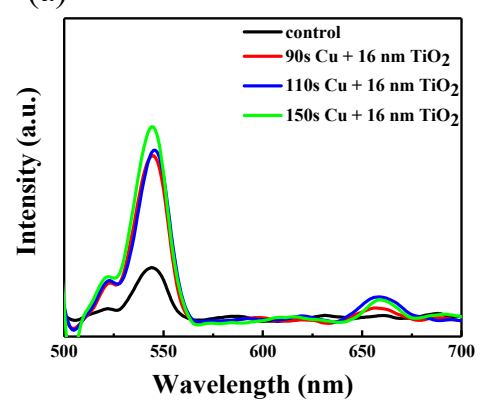

(b)

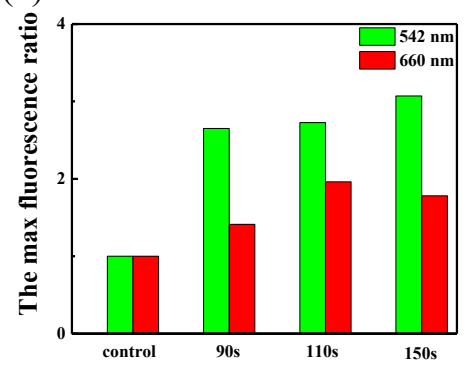

Figure 7. (a) Fluorescence spectra of $\mathrm{NaGdF}_{4}: \mathrm{Yb}$, Er on the $\mathrm{Cu} / \mathrm{TiO}_{2}$ composite film. (b) Histograms of the maximum fluorescence intensity ratio between $542 \mathrm{~nm}$ and $660 \mathrm{~nm}$ emission.

\section{Conclusions}

In this work, the $\mathrm{Cu} / \mathrm{TiO}_{2}$ hybrid film was successfully synthesized which the copper nanoparticles prepared by sputtering and the $\mathrm{TiO}_{2}$ film used by spin-coating. The evolutions of the morphological and optical properties of copper nanoparticles and $\mathrm{TiO}_{2}$ were studied. We concluded that the maximum absorption of the $\mathrm{Cu} / \mathrm{TiO}_{2}$ hybrid film appeared at about $835 \mathrm{~nm}$, and it redshift about $235 \mathrm{~nm}$ more than the absorption of pure copper nanoparticles. The changing of absorption is mainly related to the different thickness of $\mathrm{TiO}_{2}$ on the copper nanoparticles. As the same time, the position of the maximum absorbance of hybrid film matches with the excitation of the up-conversion. Thus, the fluorescence of up-conversion material enhanced and the maximum ratios of intensity of fluorescence at $542 \mathrm{~nm}$ and $650 \mathrm{~nm}$ were 3.1 and 1.9, respectively. The enhanced fluorescence was related to the surface plasmon which was mainly from the excitation field enhancement due to the modulation of dielectric environment by changing the $\mathrm{TiO}_{2}$ layer's thickness. Because of this simple and feasible way to enhance the up-conversion fluorescence, the fabrication of $\mathrm{Cu} / \mathrm{TiO}_{2}$ film is expected to be used in bioprobes for optical tracking, solar cells effective for absorbed infrared light and anti-counterfeiting technology.

Author Contributions: Conceptualization and supervision, J.T. and L.A.B.; methodology, Y.P.; writing一original draft preparation, Y.P. and B.L.; writing—review and editing, L.C. and J.L.; funding acquisition, J.T. and L.A.B. All authors have read and agreed to the published version of the manuscript.

Funding: This work was supported by (1) State Key Project of International Cooperation Research (2017YFE0108300, 2016YFE0110800); (2) National Natural Science Foundation of China (51473082); (3) The Program for Introducing Talents of Discipline to Universities ("111" plan); (4) The Double Hundred Foreign Expert Project of Shandong Province; (5) 1st Class Discipline Program of Materials Science of Shandong Province, China.

Conflicts of Interest: The authors declare no conflict of interest.

\section{References}

1. Fang, Z.; Zhen, Y.-R.; Fan, L.; Zhu, X.; Nordlander, P. Tunable wide-angle plasmonic perfect absorber at visible frequencies. Phys. Rev. B 2012, 85, 1-7. [CrossRef]

2. Lu, C.Y.; Browne, D.E.; Yang, T.; Pan, J.W. Demonstration of a compiled version of Shor's quantum factoring algorithm using photonic qubits. Phys. Rev. Lett. 2007, 99, 250504. [CrossRef] [PubMed]

3. Zhang, Y.; Aslan, K.; Previte, M.J.R.; Geddes, C.D. Metal-enhanced fluorescence from copper substrates. Appl. Phys. Lett. 2007, 90,1-3. [CrossRef] 
4. Jing, Z.; Zhuang, L.; Li, F. Upconversion Nanophosphors for Small-Animal Imaging. Chem. Soc. Rev. 2012, 41, 1323-1349. [CrossRef]

5. Jiao, J.; Li, Y.; Shen, W.; Gai, S.; Tang, J.; Wang, Y.; Huang, L.; Liu, J.; Wang, W.; Belfiore, L.A. Fabrication and luminescence of $\mathrm{KGdF}_{4}: \mathrm{Yb}^{3+} / \mathrm{Er}^{3+}$ nanoplates and their improving performance for polymer solar cells. Sci. Bull. 2018, 63, 216-218. [CrossRef]

6. Deng, R.; Qin, F.; Chen, R.; Huang, W.; Hong, M.; Liu, X. Temporal full-colour tuning through non-steady-state upconversion. Nat. Nanotechnol. 2015, 10, 237-242. [CrossRef]

7. Zhang, Y.; Zhang, L.; Deng, R.; Tian, J.; Zong, Y.; Jin, D.; Liu, X. Multicolor Barcoding in a Single Upconversion Crystal. J. Am. Chem. Soc. 2014, 136, 4893-4896. [CrossRef]

8. Haase, P.D.M.; Schfer, D.H. Upconverting Nanoparticles. Angew. Chem. Int. Ed. 2011, 50, 5808-5829. [CrossRef]

9. Li, Y.; Jiao, J.; Yan, P.; Liu, L.; Wang, J.; Wang, Y.; Huang, L.; Liu, J.; Belfiore, L.A.; Tang, J. Synthesis and tunable photoresponse for core-shell structured $\mathrm{NaGdF}_{4}: \mathrm{Yb}, \mathrm{Er} @ \mathrm{SiO}_{2} @ \mathrm{Eu}(\mathrm{TTA})_{3}$ Phen nanocomplexes. Scr. Mater. 2018, 152, 1-5. [CrossRef]

10. Guo, H.; Li, Z.; Qian, H.; Hu, Y.; Niagara Muhammad, I. Seed-mediated synthesis of $\mathrm{NaYF}_{4}: \mathrm{Yb}_{\text {, }}$ $\mathrm{Er} / \mathrm{NaGdF}_{4}$ nanocrystals with improved upconversion fluorescence and MR relaxivity. Nanotechnology 2010, 21, 125602. [CrossRef]

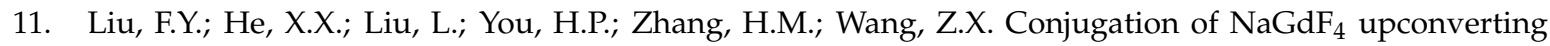
nanoparticles on silica nanospheres as contrast agents for multi-modality imaging. Biomaterials 2013, 34, 5218-5225. [CrossRef] [PubMed]

12. Chen, G.; Ohulchanskyy, T.Y.; Law, W.C.; Ågren, H.; Prasad, P.N. Monodisperse $\mathrm{NaYbF}_{4}: \mathrm{Tm}^{3+} / \mathrm{NaGdF}_{4}$ core/shell nanocrystals with near-infrared to near-infrared up-conversion photoluminescence and magnetic resonance properties. Nanoscale 2011, 3, 2003-2008. [CrossRef] [PubMed]

13. Chung, W.J.; Yoo, J.R.; Kim, Y.S.; Heo, J. Mechanism of the blue up-conversion in $\mathrm{Tm}^{3+} / \mathrm{Nd}^{3+}$-doped calcium aluminate glasses. J. Am. Ceram. Soc. 2010, 80, 1485-1490. [CrossRef]

14. Ren, G.; Zeng, S.; Hao, J. Tunable Multicolor Upconversion Emissions and Paramagnetic Property of Monodispersed Bifunctional Lanthanide-Doped NaGdF 4 Nanorods. J. Phys. Chem. C 2011, 115, 20141-20147. [CrossRef]

15. Li, H.; Deng, Q.; Liu, B.; Yang, J.; Wu, B. Fabrication of core@spacer@shell Aunanorod@mSiO $\mathrm{m}_{2} @ \mathrm{Y}_{2} \mathrm{O}_{3}$ : Er nanocomposites with enhanced upconversion fluorescence. RSC Adv. 2016, 6, 13343-13348. [CrossRef]

16. Cheng, Y.; Sun, K. Enhanced Up-Conversion Emission in $\mathrm{Al}^{3+}$ Co-Doped $\mathrm{ZnGa}_{2} \mathrm{O}_{4}: \mathrm{Yb}^{3+}, \mathrm{Tm}^{3+}$ Powder Phosphors. J. Fluoresc. 2018, 28, 801-808. [CrossRef]

17. Wu, X.; Yin, S.; Dong, Q.; Liu, B.; Wang, Y.; Sekino, T.; Lee, S.W.; Sato, T. UV, visible and near-infrared lights induced NOx destruction activity of (Yb, Er)-NaYF $/ \mathrm{C}_{4}-\mathrm{TiO}_{2}$ composite. Sci. Rep. 2013, 3, 2918. [CrossRef]

18. Zhang, F.; Wan, Y.; Yu, T.; Zhang, F.; Shi, Y.; Xie, S.; Li, Y.; Xu, L.; Tu, B.; Zhao, D. Uniform nanostructured arrays of sodium rare-earth fluorides for highly efficient multicolor upconversion luminescence. Angew. Chem. Int. Ed. 2007, 46, 7976-7979. [CrossRef]

19. Avnir, D.; Kaufman, V.R.; Reisfeld, R. Organic fluorescent dyes trapped in silica and silica-titania thin films by the sol-gel method. Photophysical, film and cage properties. J. Non Cryst. Solids 1985, 74, 395-406. [CrossRef]

20. Resch-Genger, U.; Grabolle, M.; Cavaliere-Jaricot, S.; Nitschke, R.; Nann, T. Quantum dots versus organic dyes as fluorescent labels. Nat. Methods 2008, 5, 763-775. [CrossRef]

21. Wilson, L.R.; Richards, B.S. Measurement method for photoluminescent quantum yields of fluorescent organic dyes in polymethyl methacrylate for luminescent solar concentrators. Appl. Opt. 2009, 48, 212-220. [CrossRef] [PubMed]

22. Reiss, P.; Protière, M.; Li, L. Core/Shell Semiconductor Nanocrystals. Small 2009, 5, 154-168. [CrossRef] [PubMed]

23. Bruchez, M.P. Semiconductor Nanocrystals as Fluorescent Biological Labels. Science 1998, 281, $2013-2016$. [CrossRef] [PubMed]

24. Macdougall, S.K.W.; Ivaturi, A.; Marques-Hueso, J.; Krämer, K.W.; Richards, B.S. Ultra-high photoluminescent quantum yield of $\beta-\mathrm{NaYF}_{4}: 10 \% \mathrm{Er}^{3+}$ via broadband excitation of upconversion for photovoltaic devices. Opt. Express 2012, 20, A879. [CrossRef] [PubMed]

25. Liedberg, B.; Lundström, I.; Stenberg, E. Principles of biosensing with an extended coupling matrix and surface plasmon resonance. Sens. Actuators, B 1993, 11, 63-72. [CrossRef] 
26. Hutter, E.; Fendler, J.H. Exploitation of Localized Surface Plasmon Resonance. Adv. Mater. 2004, 16, $1685-1706$. [CrossRef]

27. Arppe, R.; Sørensen, T.J. Physical unclonable functions generated through chemical methods for anti-counterfeiting. Nat. Rev. Chem. 2017, 1, 0031. [CrossRef]

28. Barnes, W.L.; Dereux, A.; Ebbesen, T.W. Surface plasmon subwavelength optics. Nature. 2003, 424, 824-830. [CrossRef]

29. Homola, J.; Yee, S.S.; Gauglitz, G. Surface Plasmon Resonance Sensors: Review. Anal. Bioanal. Chem. 1999, 377, 528-539. [CrossRef]

30. Homola, J. Present and future of surface plasmon resonance biosensors. Anal. Bioanal. Chem. 2003, 377, 528-539. [CrossRef]

31. Futamata, M.; Maruyama, Y.; Ishikawa, M. Local Electric Field and Scattering Cross Section of Ag Nanoparticles under Surface Plasmon Resonance by Finite Difference Time Domain Method. J. Phys. Chem. B 2003, 107, 7607-7617. [CrossRef]

32. Suyver, J.F.; Aebischer, A.; Biner, D.; Gerner, P.; Grimm, J.; Heer, S.; Krämer, K.W.; Reinhard, C.; Güdel, H.U. Novel materials doped with trivalent lanthanides and transition metal ions showing near-infrared to visible photon upconversion. Opt. Mater. 2005, 27, 1111-1130. [CrossRef]

33. Hong, Y.P.; Dwight, K. Crystal structure and fluorescence lifetime of a laser material $\mathrm{NdNa}_{5}\left(\mathrm{WO}_{4}\right)_{4}$. Mater. Res. Bull. 1974, 9, 775-780. [CrossRef]

34. Manurung, R.V.; Wu, C.T.; Roy, P.K.; Chattopadhyay, S. A plasmon-tuned 'gold sandwich' for metal enhanced fluorescence in silica coated $\mathrm{NaYF}_{4}: \mathrm{Yb}$,Er upconversion nanoparticles. RSC Adv. 2016, 6, 87088-87095. [CrossRef]

35. Chen, X.; Zhou, D.; Xu, W.; Zhu, J.; Pan, G.; Yin, Z.; Wang, H.; Zhu, Y.; Shaobo, C.; Song, H. Fabrication of Au-Ag nanocage@NaYF$@ \mathrm{NaYF}_{4}: \mathrm{Yb}$,Er Core-Shell Hybrid and its Tunable Upconversion Enhancement. Sci. Rep. 2017, 7, 41079. [CrossRef]

36. Wang, H.; Li, M.; Yin, Z.; Zhang, T.; Chen, X.; Zhou, D.; Zhu, J.; Xu, W.; Cui, H.; Song, H. Remarkable Enhancement of Upconversion Luminescence on Cap-Ag/PMMA Ordered Platform and Trademark Anticounterfeiting. ACS Appl. Mater. Interfaces 2017, 9, 37128-37135. [CrossRef]

37. Sui, M.; Zhang, Q.; Kunwar, S.; Pandey, P.; Li, M.-Y.; Lee, J. Study on the dimensional, configurational and optical evolution of palladium nanostructures on c-plane sapphire by the control of annealing temperature and duration. Appl. Surf. Sci. 2017, 416, 1-13. [CrossRef]

38. Thompson, C.V. Solid-State Dewetting of Thin Films. Annu. Rev. Mater. Res. 2012, 42, 399-434. [CrossRef]

39. Zhao, X.; Lee, U.-J.; Lee, K.-H. Dewetting behavior of Au films on porous substrates. Thin Solid Films 2010, 519, 706-713. [CrossRef]

40. Pandey, P.; Sui, M.; Zhang, Q.; Li, M.-Y.; Kunwar, S.; Lee, J. Systematic control of the size, density and configuration of Pt nanostructures on sapphire $\left(\begin{array}{llll}0 & 0 & 0 & 1\end{array}\right)$ by the variation of deposition amount and dwelling time. Appl. Surf. Sci. 2016, 368, 198-207. [CrossRef]

41. Yao, J.H.; Elder, K.R.; Guo, H.; Grant, M. Theory and simulation of Ostwald ripening. Phys. Rev. B 1993, 47, 14110-14125. [CrossRef] [PubMed]

42. Marqusee, J.A.; Ross, J. Theory of Ostwald ripening: Competitive growth and its dependence on volume fraction. J. Chem. Phys. 1984, 80, 536-543. [CrossRef]

43. Zhan, Q.; Zhang, X.; Zhao, Y.; Liu, J.; He, S. Tens of thousands-fold upconversion luminescence enhancement induced by a single gold nanorod. Laser Photonics Rev. 2015, 9, 479-487. [CrossRef]

44. Chen, H.; Shao, L.; Li, Q.; Wang, J. Gold nanorods and their plasmonic properties. Chem. Soc. Rev. 2013, 42, 2679-2724. [CrossRef] [PubMed]

45. Ruan, Q.; Shao, L.; Shu, Y.; Wang, J.; Wu, H. Growth of Monodisperse Gold Nanospheres with Diameters from $20 \mathrm{~nm}$ to $220 \mathrm{~nm}$ and Their Core/Satellite Nanostructures. Adv. Opt. Mater. 2014, 2, 65-73. [CrossRef]

46. Rostovshchikova, T.N.; Smirnov, V.V.; Kozhevin, V.M.; Yavsin, D.A.; Zabelin, M.A.; Yassievich, I.N.; Gurevich, S.A. New size effect in the catalysis by interacting copper nanoparticles. Appl. Catal. A 2005, 296, 70-79. [CrossRef]

47. Mao, S.; Liu, J.; Pan, Y.; Lee, J.; Yao, Z.; Pandey, P.; Kunwar, S.; Zhu, Z.; Shen, W.; Belfiore, L.A.; et al. Morphological and optical evolution of metallic oxide/Au nanoparticle hybrid thin film: High absorption and reflectance by plasmonic enhancement. Appl. Surf. Sci. 2019, 495, 143575. [CrossRef] 
48. Lv, B.; Jiao, J.; Liu, Y.; Liu, L.; Zhang, J.; Li, Y.; Wang, J.; Tang, J. Heterostructure NaGdF 4 :Yb,Er anchored on MIL-101 for promoting photoelectronic response and photocatalytic activity. Nanoscale 2019, 11, 22730-22733. [CrossRef]

49. Liang, Z.; Sun, E.; Liu, Z.; Zhang, Z.; Zeng, J.; Ruan, W.; Li, G.; Cao, W. Electric field induced upconversion fluorescence enhancement and its mechanism in $\mathrm{Er}^{3+}$ doped $0.75 \mathrm{~Pb}\left(\mathrm{Mg}_{1 / 3} \mathrm{Nb}_{2 / 3}\right) \mathrm{O}_{3}-0.25 \mathrm{PbTiO}_{3}$ transparent ceramic. Appl. Phys. Lett. 2016, 109, 132904. [CrossRef]

50. Maurya, S.K.; Tiwari, S.P.; Kumar, A.; Kumar, K. Plasmonic enhancement of upconversion emission in $\mathrm{Ag} @ \mathrm{NaYF}_{4}: \mathrm{Er}^{3+} / \mathrm{Yb}^{3+}$ phosphor. J. Rare Earths 2018, 36, 903-910. [CrossRef]

(C) 2020 by the authors. Licensee MDPI, Basel, Switzerland. This article is an open access article distributed under the terms and conditions of the Creative Commons Attribution (CC BY) license (http://creativecommons.org/licenses/by/4.0/). 